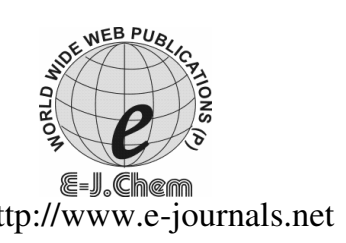

ISSN: 0973-4945; CODEN ECJHAO

E-Journal of Chemistry 2009, 6(2), 247-256

\title{
Removal of Lead(II) Ions by Adsorption onto Bamboo Dust and Commercial Activated Carbons -A Comparative Study
}

\author{
N. KANNAN* and T. VEEMARAJ \\ Centre for Research \& Post Graduate Studies in Chemistry, \\ Ayya Nadar Janaki Ammal College (Autonomous), \\ Sivakasi - 626 124, Tamil Nadu, India. \\ dr_n_kannan@yahoo.co.in
}

Received 13 August 2008; Accepted 4 October 2008

\begin{abstract}
Studies on the removal of lead(II) ions by adsorption onto indigenously prepared bamboo dust carbon (BDC) and commercial activated carbon (CAC) have been carried out with an aim to obtain data for treating effluents from metal processing and metal finishing industries. Effect of various process parameters has been investigated by following the batch adsorption technique at $30 \pm 1^{\circ} \mathrm{C}$. Percentage removal of lead(II) ions increased with the decrease in initial concentration and increased with increase in contact time and dose of adsorbent. Amount of lead(II) ions adsorbed increases with the decrease in particle size of the adsorbent. As initial $\mathrm{pH}$ of the slurry increased, the percentage removal increased, reached a maximum and the final solution $\mathrm{pH}$ after adsorption decreases. Adsorption data were modeled with the Freundlich and Langmuir isotherms, the first order kinetic equations proposed by Natarajan - Khalaf, Lagergren and Bhattacharya and Venkobachar and intra- particle diffusion model and the models were found to be applicable. Kinetics of adsorption is observed to be first order with intra-particle diffusion as one of the rate determining steps. Removal of lead(II) ions by bamboo dust carbon (BDC) is found to be favourable and hence BDC could be employed as an alternative adsorbent to commercial activated carbon (CAC) for effluent treatment, especially for the removal of lead(II) ions.
\end{abstract}

Keywords: Removal of lead(II) ions, Bamboo dust carbon (BDC) and commercial activated carbon (CAC), Adsorption isotherms, Kinetic equations, Intra-particle diffusion model. 


\section{Introduction}

In developing countries like India, the development of indigenous low - cost materials for the water and wastewater treatment is essentially needed, because the commercially available commercial activated carbon (CAC) is highly costly and the difficulty exists in its procurement in developing countries like India. Heavy metal ions, especially lead(II) ions are highly toxic to the living beings, especially to the aquatic plants and animals, and therefore to be necessarily removed from water and wastewater ${ }^{1}$.

India is basically an agricultural country with plenty of agricultural wastes. At present there is an urgent need to develop new cheaper indigenously prepared activated carbons (IPACs) from the abundant agricultural wastes ${ }^{2}$. Agricultural by-products and some industrial wastes contain high carbon content and hence they could be used as starting/raw materials for the preparation of IPACs.

Although some attempts have already been made to economize the activated carbon (AC), the scope for minimizing its cost and development of alternative adsorbent materials to CAC by preparing IPACs from agricultural wastes is still open. Several attempts have been made to prepare carbons from unconventional raw materials like saw dust ${ }^{3}$, cow dung ${ }^{4}$, rice husk ${ }^{5}$, waste tea leaves ${ }^{6}$, wood charcoal $^{7}$, and rice hull were prepared by activation with and without $\mathrm{ZnCl}_{2}$ at different temperatures ${ }^{8}$. Activated ground nut husk carbon', AC prepared from Streculia feetida $\mathrm{L}$ (Seema Badam) fruit shel1 ${ }^{10}$, IPACs prepared from kapok fruit coat, cashew nut shells and coconut shells ${ }^{11}$ and chemically prepared ACs prepared from straw, and dates nut ${ }^{12}$ and coconut shell and dates nut ${ }^{13}$ were also used for the removal of metal ions like $\mathrm{Hg}^{2+}$, $\mathrm{Pb}^{2+}, \mathrm{Ca}^{2+}$ and $\mathrm{Cu}^{2+}$ ions. The reported results revealed that carbons prepared from agricultural wastes exhibit a high adsorption capacity, obeyed Langmuir and Freundlich isotherms, first order kinetic equations and found to be $\mathrm{pH}$ sensitive towards the removal of metal ions. Carbons prepared from these agricultural wastes are found to be porous in nature with high surface area and hence suitable for the removal of metal ions. Based on this idea, the present work is an attempt to indigenously prepare activated carbon from the locally available agricultural wastes viz., bamboo dust, to study the suitability of bamboo dust carbon (BDC) for the removal of lead(II) ions by determining the effect of various process parameters like initial concentration, contact time, dose, particle size and initial $\mathrm{pH}$ on the extent of removal of lead(II) ions and to model the adsorption data with various isotherms and first order kinetic equations and to compare the data with that of CAC.

\section{Experimental}

\section{Reagents}

CAC was procured commercially from BDH, India. Raw material for the preparation of BDC viz., bamboo dust was colleted locally, cleaned, dried and cut into small pieces before carbonization. All the chemicals used were of analytical grade reagent obtained from both SD fine chemicals and Fischer, India. Double distilled (DD) water ${ }^{14}$ was used throughout the experiments. Lead(II) nitrate (BDH, AR) was used as a source of lead(II) ions.

\section{Adsorbent}

The raw material, viz., bamboo dust (BD), was carbonized with sodium bicarbonate at $300-400^{\circ} \mathrm{C}$ and kept at $600^{\circ} \mathrm{C}$ in a muffle furnace (Neolab, India) to get carbon. The carbon was sieved ( $\mathrm{CAC}=90$ micron and $\mathrm{BDC}=45-250$ micron); activated by digesting it with $4 \mathrm{~N}$ nitric acid solution for $2 \mathrm{~h}$ at $80^{\circ} \mathrm{C}$ and finally activated in an air - oven for $5 \mathrm{~h}$ at $120^{\circ} \mathrm{C}$. BDC was stored in an airtight wide mouth reagent bottles and used for adsorption studies. CAC was also acid digested and stored. 


\section{Adsorption experiments}

Adsorption experiments were carried out at room temperature $\left(30 \pm 1^{\circ} \mathrm{C}\right)$ under batch mode ${ }^{15,16}$. Stock solution of lead(II) nitrate was prepared suitably diluted with DD water and estimated by EDTA method using xylenol orange, as indicator. Exactly $50 \mathrm{~mL}$ of lead(II) ion solution of known initial concentration was shaken with a required dose of adsorbent (CAC $=4-22 \mathrm{~g} / \mathrm{L}$ and $\mathrm{BDC}=10-28 \mathrm{~g} / \mathrm{L})$ of a fixed particle size $(\mathrm{CAC}=90$ micron and $\mathrm{BDC}=45-250$ micron $)$ in a thermostatic orbit incubator shaker (Neolab, India) at $200 \mathrm{rpm}$ after noting down the initial $\mathrm{pH}$ of the solution ( $\mathrm{pH}=7.2$ ). The initial $\mathrm{pH}$ was adjusted to the required $\mathrm{pH}$ value (range: $2-8$ ) by adding either $1 \mathrm{M} \mathrm{HCl}$ or $1 \mathrm{M} \mathrm{NaOH}$ solution. After equilibration, the final concentrations $\left(\mathrm{C}_{\mathrm{e}}\right)$ were also measured complexometrically. The value of percentage removal and amount adsorbed ( $\mathrm{q}$ in $\mathrm{mg} / \mathrm{g}$ ) were calculated using the following relationships:

$$
\begin{aligned}
\text { Percentage removal } & =100\left(\mathrm{C}_{\mathrm{i}}-\mathrm{C}_{\mathrm{e}}\right) / \mathrm{C}_{\mathrm{i}} \\
\text { Amount adsorbed }(\mathrm{q}) & =\left(\mathrm{C}_{\mathrm{i}}-\mathrm{C}_{\mathrm{e}}\right) / \mathrm{m}
\end{aligned}
$$

where, $\mathrm{C}_{\mathrm{i}}$ and $\mathrm{C}_{\mathrm{e}}$ are initial and equilibrium (final) concentration of lead(II) ions (ppm), respectively and $\mathrm{m}$ is the mass of adsorbent, in $\mathrm{g} / \mathrm{L}$.

The adsorption isotherms were specified at $\mathrm{pH} 7.2$ for BDC and CAC. Absorption data obtained from the effect of initial concentration and contact time were employed in testing the applicability of isotherms and kinetic equations, respectively.

\section{Results and Discussion}

\section{Effect of Initial concentration}

The adsorption experiments were carried out under batch mode at different experimental conditions (Table 1) and the results obtained are discussed below. The results on the extent of removal (\% removal) of lead(II) ions under various experimental conditions are given in Table 1. The effect of initial concentration is shown in Figure 1.

The percentage removal decreased with the increase in initial concentration of lead(II) ions. This may probably be due to the limited number of available active sites on the surface of CAC and BDC to accommodate higher concentration of lead(II) ions. The optimum initial concentration of lead(II) ions is fixed as $600 \mathrm{ppm}$ for both BDC and CAC.

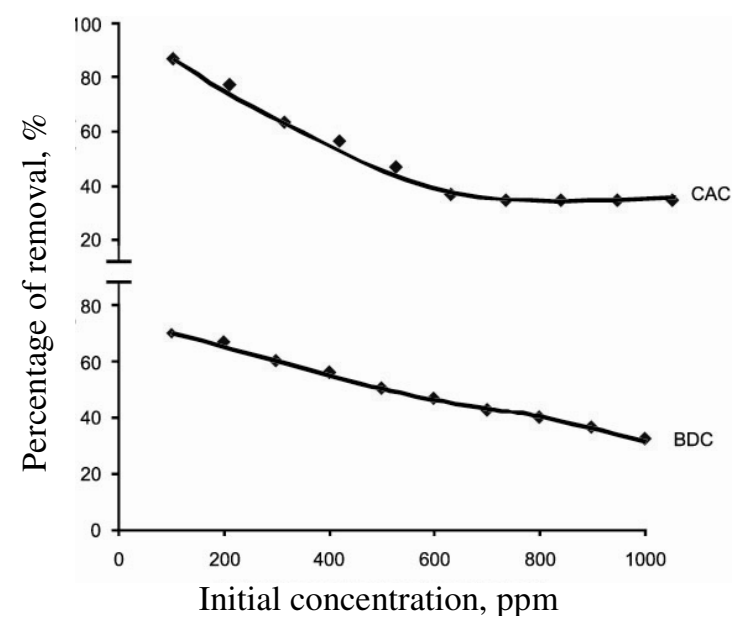

Figure 1. Effect of Initial concentration on the removal of lead(II) ions by BDC and CAC. 
Table 1. Effect of initial concentration for the extent of removal of lead(II) ions by CAC and $\mathrm{BDC}$ at $30^{\circ} \mathrm{C}$

\begin{tabular}{lccc}
\hline \multirow{2}{*}{ Process parameter } & \multirow{2}{*}{ Range } & \multicolumn{2}{c}{ Percentage of Removal } \\
\cline { 3 - 4 } & $100-1000$ & $86.9-34.5$ & $70.06-31.80$ \\
Initial conc, ppm & $5-55$ & $59.4-84.4$ & $17.94-62.29$ \\
Contact time, min. & $4-22(\mathrm{CAC}) ; 10-28$ (BDC) & $28.5-87.7$ & $31.24-71.17$ \\
Dose of adsorbent, g/L & $2.0-8.0$ & $32.0-92.15$ & $13.51-66.64$ \\
Initial pH & $45-250$ & - & $49.12-17.94$ \\
Particle size, $\mu$ & &
\end{tabular}

\section{Adsorption Isotherms}

Adsorption data were modeled with the help of Freundlich and Langmuir isotherms ${ }^{17}$. The adsorption data were flitted with these isotherms (a) by plotting the values of $\log \mathrm{q}_{\mathrm{e}} v s \log \mathrm{C}_{\mathrm{e}}$ and $\left(\mathrm{C}_{\mathrm{e}} / \mathrm{q}_{\mathrm{e}}\right)$ vs $\mathrm{C}_{\mathrm{e}}$ and (b) by carrying out correlation analysis between the values of (i) $\log \mathrm{q}_{\mathrm{e}}$ and $\log \mathrm{c}_{\mathrm{e}}$ and (ii) $\left(\mathrm{C}_{\mathrm{e}} / \mathrm{q}_{\mathrm{e}}\right)$ and $\mathrm{C}_{\mathrm{e}}$ (Table 2).

Freundlich isotherm: $\log q=\log K+(1 / n) \log C_{e}$

Langmuir isotherm: $\left(\mathrm{C}_{\mathrm{e}} / \mathrm{q}\right)=\left(1 / \mathrm{Q}_{\mathrm{o}} \mathrm{b}\right)+\left(\mathrm{C}_{\mathrm{e}} / \mathrm{Q}_{\mathrm{o}}\right)$

where, $\mathrm{K}$ and $1 / \mathrm{n}$ are the measures of adsorption capacity and intensity of adsorption, respectively ; $\mathrm{q}$ is the amount adsorbed per unit mass of adsorbent (in $\mathrm{mg} / \mathrm{g}$ ); $\mathrm{Q}_{\mathrm{o}}$ and $\mathrm{b}$ are Langmuir constants, which are the measures of monolayer adsorption capacity (in $\mathrm{mg} / \mathrm{g}$ ) and surface energy $(\mathrm{L} / \mathrm{mg})$, respectively. The results of correlation analysis along with the isotherm parameters are given in Table 2. The observed linear relationships are statistically significant as evidenced from the correlation coefficients (r-values) close to unity, which indicate the applicability of these two adsorption isotherms and the monolayer coverage of lead species on the carbon surface. The monolayer adsorption capacity, $\mathrm{Q}_{0}$ value (Table 2) indicates that BDC is a better adsorbent for lead(II) ions.

Further, the essential characteristics of the Langmuir isotherm can be described by a separation factor, $\mathrm{R}_{\mathrm{L}}$, which is defined by the following equation ${ }^{18-20}$.

$$
\mathrm{R}_{\mathrm{L}}=1 /(1+\mathrm{bCi})
$$

Table 2. Adsorption isotherm data for removal of lead(II) ions by $\mathrm{CAC}$ and $\mathrm{BDC}$ at $30^{\circ} \mathrm{C}$

\begin{tabular}{clcc}
\hline S.No. & \multicolumn{1}{c}{ Parameters } & CAC & BDC \\
\hline 1. & Freundlich isotherm & & \\
& Slope $(1 / \mathrm{n})$ & 0.810 & 0.298 \\
& Intercept $(\log \mathrm{K})$ & 0.590 & 3.302 \\
& Correlation coefficient $(\mathrm{r})$ & 0.997 & 0.992 \\
\hline
\end{tabular}

\section{Langmuir isotherm}

$\begin{array}{lll}\text { Slope }\left(1 / \mathrm{Q}_{\mathrm{o}}\right) & 0.168 & 0.465 \\ \text { Intercept }\left(1 / \mathrm{Q}_{\mathrm{o}} \mathrm{b}\right) & 0.126 & 0.265 \\ \text { Correlation coefficient }(\mathrm{r}) & 0.992 & 0.997 \\ \mathrm{~b}, \mathrm{~L} / \mathrm{mg} & 1.330 & 0.569 \\ \mathrm{Q}_{\mathrm{o}}, \mathrm{mg} / \mathrm{g} & 5.950 & 2.151 \\ \mathrm{RL} & 0.746 & 0.997\end{array}$

The separation factor, $\mathrm{R}_{\mathrm{L}}$, indicate the shape of the isotherm and the nature of the adsorption process as given below: 


$\begin{array}{ll}\mathbf{R}_{\mathbf{L}} \text { value } & \text { Nature of the process } \\ \mathrm{R}_{\mathrm{L}}>1 & \text { Unfavourable } \\ \mathrm{R}_{\mathrm{L}}>1 & \text { Linear } \\ 0>\mathrm{R}_{\mathrm{L}}>1 & \text { Favourable } \\ \mathrm{R}_{\mathrm{L}}>0 & \text { Irreversible }\end{array}$

In the present study, the computed values of $\mathrm{R}_{\mathrm{L}}$ (Table 2) are found to be fraction in the range of $0-1$, indicating that the adsorption process is favorable for these adsorbents for the removal of lead(II) ions.

\section{Effect of contact time}

The percentage removal increased with increase in contact time and reached a constant value. This may be due to the attainment of equilibrium condition at $35 \mathrm{~min}$ of contact time for $\mathrm{CAC}$ and $45 \mathrm{~min}$ of contact time for $\mathrm{BDC}$, which are fixed as the optimum contact time.

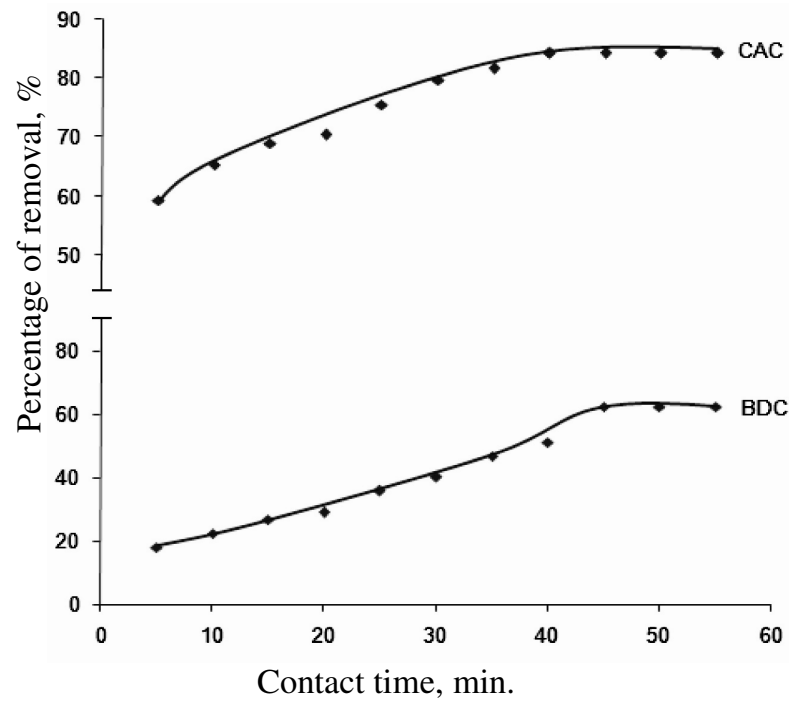

Figure 2. Effect of contact time on the removal of lead(II) ions by BDC and CAC

The effect of contact time is shown in Figure 2. At the initial stage, the rate of removal of lead(II) ions was higher, due to the availability of more than required number of active sites on the surface of carbons and became slower at the later stages of contact time, due to the decreased or lesser number of active $\operatorname{sites}^{21}$. Similar results have been reported in literature for the removal of dyes ${ }^{22}$, organic acids ${ }^{23}$ and metal ions ${ }^{24}$ by various adsorbents.

\section{Kinetics of Adsorption}

The kinetics of adsorption of lead(II) ions by BDC and CAC has been studied by testing the applicability of various first order kinetic equations proposed by Natarajan and Khalaf, Lagergren as cited by Pandey, et al., ${ }^{25}$ and Bhattacharya and Venkobachar ${ }^{26}$.

Natarajan and Khalaf eqn:

$$
\log \left(\mathrm{C}_{\mathrm{i}} / \mathrm{C}_{\mathrm{t}}\right)=(\mathrm{k} / 2.303) \mathrm{t}
$$

Lagergren eqn:

$$
\log \left(\mathrm{q}_{\mathrm{e}}-\mathrm{q}_{\mathrm{t}}\right)=\log \mathrm{q}_{\mathrm{e}}-(\mathrm{k} / 2.303) \mathrm{t}
$$




$$
\begin{aligned}
& \text { Bhattacharya \& Venkobachar eqn: } \\
& \qquad \log (1-\mathrm{U}(\mathrm{T}))=-(\mathrm{k} / 2.303) \mathrm{t}
\end{aligned}
$$

where, $U(T)=\left[\left(C_{i}-C_{t}\right) /\left(C_{i}-C_{e}\right)\right] ; C_{i}, C_{t}$ and $C_{e}$ are the concentration of lead(II) ions (in $\mathrm{mg} / \mathrm{L}$ ) at time zero, time, $\mathrm{t}$, and at equilibrium time; $\mathrm{q}_{\mathrm{e}}$ and $\mathrm{q}_{\mathrm{t}}$ are the amount adsorbed per unit mass of adsorbent (in $\mathrm{mg} / \mathrm{g}$ ) and at time $\mathrm{t}$, respectively; and $\mathrm{k}$ is the first order rate constant (in/min) for adsorption of lead(II) ions. The values of first order rate constants are given in Table 3. All linear correlations are found to be statistically significant as evidenced by $r$ - values close to unity. The results indicate the first order nature of adsorption process and applicability of these kinetic equations. The $\mathrm{k}$ values calculated from Bhattacharya and Venkobachar equation are noted to be close to that of the $\mathrm{k}$ values computed from Lagergren equation, for any given adsorbent. This conclude that, in future any one of these two kinetic equations can be employed to calculated the $\mathrm{k}$ values in adsorption process of metal ions, in general and lead(II) ions, in particular.

\begin{tabular}{|c|c|c|c|}
\hline S.No & Parameter & $\mathrm{CAC}$ & $\mathrm{BDC}$ \\
\hline \multirow{3}{*}{1.} & Natarajan - Khalaf eqn. & & \\
\hline & Correlation coefficient (r) & 0.994 & 0.990 \\
\hline & $10^{3} \mathrm{k}, / \mathrm{min}$ & 27.11 & 0.007 \\
\hline \multirow[t]{3}{*}{2.} & Lagergren equation & & \\
\hline & Correlation coefficient $(r)$ & 0.965 & 0.991 \\
\hline & $10^{2} \mathrm{k}, / \mathrm{min}$ & 7.26 & 0.001 \\
\hline \multirow[t]{3}{*}{3.} & Bhattacharya \& Venkobachar eqn. & & \\
\hline & Correlation coefficient $(r)$ & 0.966 & 0.990 \\
\hline & $10^{2} \mathrm{k}, / \mathrm{min}$ & 7.25 & 0.017 \\
\hline \multirow[t]{5}{*}{4.} & Intra - particle diffusion model & & \\
\hline & Correlation coefficient $(r)$ & 0.993 & 0.953 \\
\hline & $10^{2} \mathrm{k}_{\mathrm{p}}, \mathrm{mg} / \mathrm{g} / \mathrm{min}^{1 / 2}$ & 1.29 & 9.387 \\
\hline & Intercept & 0.31 & 8.152 \\
\hline & $\log (\%$ removal) vs log (time) & & \\
\hline \multirow[t]{2}{*}{5.} & Correlation coefficient $(r)$ & 0.984 & 0.987 \\
\hline & Slope $(m)$ & 0.169 & 1.181 \\
\hline
\end{tabular}

Table 3. Kinetics of adsorption for removal of lead(II) ions by CAC and BDC at $30^{\circ} \mathrm{C}$

Adsorbate (lead) species are most probably transported from the bulk of the solution to the solid phase through intra- particle diffusion / transport process, which is often the rate limiting step in many adsorption processes, especially in a rapidly stirred batch reactor ${ }^{27}$.

\section{Intra-particle diffusion model}

The possibility of the presence of intra- particle diffusion as the rate limiting step was explored by using the intra- particle diffusion model ${ }^{28-29}$.

$$
\mathrm{q}_{\mathrm{t}}=\mathrm{k}_{\mathrm{p}} \mathrm{t}^{1 / 2}+\mathrm{c}
$$

where, $\mathrm{q}_{\mathrm{t}}=$ amount adsorbed in time $\mathrm{t}, \mathrm{c}=$ intercept and $\mathrm{k}_{\mathrm{p}}=$ intra- particle diffusion rate constant (in $\mathrm{mg} / \mathrm{gm} / \mathrm{min} .{ }^{0.5}$ ). The values of $\mathrm{q}_{\mathrm{t}}$ are found to be linearly correlated with values of $\mathrm{t}^{1 / 2}$. The $\mathrm{k}_{\mathrm{p}}$ values are calculated and given in Table 3 . The values of intercept (c) give an idea about the boundary layer thickness, i.e., the larger the intercept greater is the boundary layer effect. BDC is more porous than CAC. 
The correlations of the values of $\log$ (\% removal) and $\log$ (time) also resulted in linear relationships, as evidenced by $\mathrm{r}$-values close to unity ( $\mathrm{CAC}=0.984$ and $\mathrm{BDC}=0.987$ ). The divergence in the value of slope from 0.5 (slope : $\mathrm{CAC}=0.169$ and $\mathrm{BDC}=1.181$ ) indicates the presence of intra-particle diffusion as one of the rate limiting steps $^{30}$, besides many other processes controlling the rate of adsorption, all of which may be operating simultaneously.

The results of the present study conclude that, BDC could be used as an adsorbent alternative to CAC in cost - effective effluent treatment, especially for the removal of metal / lead(II) ions. The results will be highly useful in designing low- cost effluent treatment plant. Thus, results of this study will be useful in the development of strategy for the production of low cost adsorbent (BDC), which is indigenously prepared from the locally available agricultural wastes / by - product is BD.

\section{Effect of dose}

The effect of dose of adsorbent on the percentage removal of $\mathrm{Pb}^{2+}$ ions was studied. The percentage removal increased with increase in dose of adsorbent (Table 1 and Figure 3). This may be due to the rapid increase in surface area and number of available active sites for the adsorption of lead(II) ions, or due to conglomeration of carbons at higher doses ${ }^{32}$. The relative increase in the percentage removal of $\mathrm{Pb}^{2+}$ ions is found to be insignificant after a dose of $20 \mathrm{~g} / \mathrm{L}$ of BDC and $10 \mathrm{~g} / \mathrm{L}$ of CAC, which is fixed as the optimum dose. The values of $\log (\%$ removal) are also found to be linearly correlated with $\log (\operatorname{dose})$ values. The values of $\log \mathrm{q}$ are found to be linearly correlated to $\log$ (dose) with correlation coefficients, which are almost unity ( $\mathrm{r}=$ values: $\mathrm{CAC}=0.988 ; \mathrm{BDC}=0.998)$. This is in accordance with the fractional power term of the dose as:

$$
\mathrm{q}=[\mathrm{dose}]^{-\mathrm{n}}+\mathrm{c}
$$

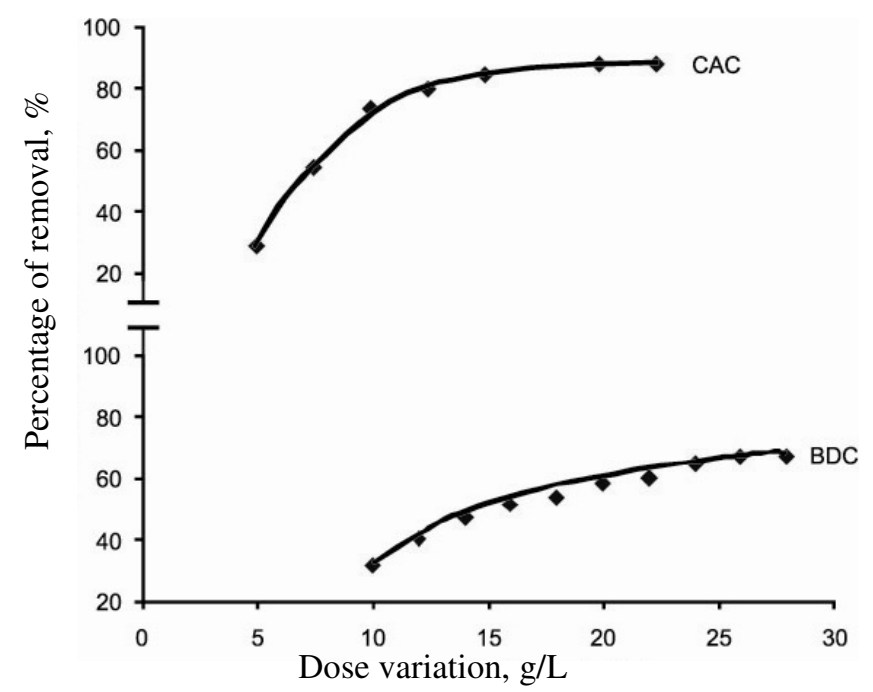

Figure 3. Effect of dose variation on the removal of lead(II) ions by BDC and CAC

This suggests that the adsorbed $\mathrm{Pb}(\mathrm{II})$ ions may either block the access to the internal pores of carbons or may cause particles to aggregate and thereby minimizing the availability of active sites for adsorption. 


\section{Effect of particle size of BDC}

The effect of particle size on the \% removal of lead(II) ions adsorbed (range) is given in the Table 1 (Figure 4). The effect of particle size on the \% removal of lead(II) ions adsorbed was studied only by varying the particle size of BDC as 45, 90, 125, 150 and 250 micron; CAC was not used, since its particle size is uniform and constant at 90 micron. The value of correlation coefficient is close to unity ( $\mathrm{r}=0.927$ ). The amount of lead(II) ions adsorbed increases with the decrease in particle size of the adsorbent. This is due to the increase in the availability surface area with the decrease in particle size.

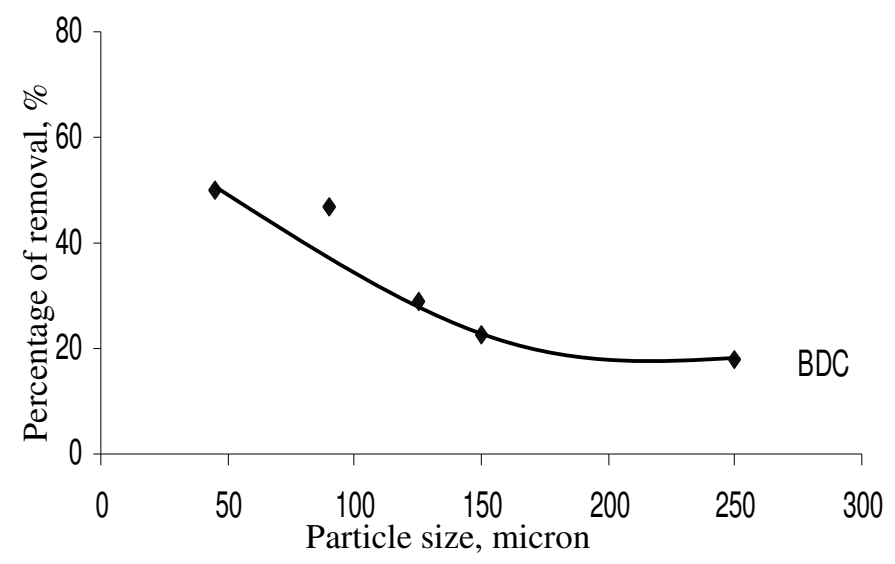

Figure 4. Effect of particle size on the removal of lead(II) ions by BDC

\section{Effect of $p H$}

The effect of initial $\mathrm{pH}$ on the extent of removal of lead(II) ions by adsorption on BDC and $\mathrm{CAC}$ at $30^{\circ} \mathrm{C}$ is given in Table 4 . The adsorption of lead(II) ions on the adsorbents are found to be highly $\mathrm{pH}$ dependent. As $\mathrm{pH}$ increases, the extent of removal increases, reaches a maximum value and then decreases further increased upto optimum $\mathrm{pH}$. The optimum $\mathrm{pH}$ for removal of $\mathrm{Pb}^{2+}$ ions is fixed as 7.2 for both $\mathrm{CAC}$ and BDC. The near neutral $\mathrm{pH}$ is found to be favourable. The $\mathrm{pH}$ value slightly decreases and change in $\mathrm{pH}(\Delta \mathrm{pH}=$ initial $\mathrm{pH}$ - final $\mathrm{pH}$ ) values after adsorption are found to decrease in the order of 0.3-0.5 units. This suggests that during the adsorption of lead species, protons are released from the surface functional groups like phenolic, carboxylic and enolic groups present on the carbons. Above $\mathrm{pH} 8.1$, the $\mathrm{Pb}^{2+}$ ions are also precipitated as lead hydroxide.

Table 4. Effect of initial $\mathrm{pH}$ on the extent of removal of lead(II) ions by $\mathrm{CAC}$ and $\mathrm{BDC}$ at $30^{\circ} \mathrm{C}$

\begin{tabular}{ccc}
\hline \multirow{2}{*}{ Initial $\mathrm{pH}$} & \multicolumn{2}{c}{ Percentage removal } \\
\cline { 2 - 3 } & \multicolumn{1}{c}{ CAC } & BDC \\
\hline 2.1 & 32.00 & 13.51 \\
3.2 & 43.17 & 20.16 \\
4.0 & 54.81 & 29.03 \\
5.0 & 61.32 & 40.12 \\
6.1 & 73.44 & 62.29 \\
7.2 & 92.15 & 66.73 \\
8.0 & 91.55 & 66.64 \\
\hline
\end{tabular}


These adsorption data suggest that BDC could be used as an adsorbent alternative to CAC for the cost effective treatment of effluents, especially for the removal of lead (II) ions.

\section{Acknowledgement}

The authors thank the Management and Principal of ANJA College, Sivakasi, for providing facilities and encouragement. The authors also thank the UGC, New Delhi, for financial assistance under UGC-Major Research Project scheme.

\section{Reference}

1. Adamson A W, Physical chemistry of surfaces; Interscience Publ. Inc. New York, 1960.

2. Pattabiraman T N, Principles of Biochemistry; Gajanana Book Publ. and Dist. Bangalore, 1993.

3. Vaisya R C and Prasad S C, Indian J Environ Protect., 1991, 11(4), 284.

4. Himesh S and Mahadeva Samy S, Indian J Environ Health, 1994, 6(3), 165.

5. Srinivasan K, Balasubramaniam N and Ramakrishna T V, Indian J Environ Health, 1988, 30(4), 376.

6. Ramu A, Kannan N and Srivathsan S A, Indian J Environ Health, 1992, 34(3), 192.

7. Deepak D and Gupta A K, Indian J Environ Health, 1991, 33, 297.

8. Cici M and Keks E, Pak J Sci Ind Res., 1990, 33, 347.

9. Periyasamy K, Srinivasan K and Murugan P K, Indian J Environ Health, 1991, 33, 433.

10. Srinivasalu A, Sundaram E V and Komal Reddy M, Indian J Environ Protect., 1998, 18(9), 687.

11. Raja Kumar A, Kinetics of adsorption of heavy metals by activated carbons; Ph.D. Thesis, Madurai Kamaraj University, Madurai, India, 2002.

12. Rengasamy G, Studies on the dynamics of adsorption of metal ions; Ph.D. Thesis, Madurai Kamaraj University, Madurai, India, 2003.

13. Kannan N and Balamurugan J, Indian J Environ Protect, 2004, 24(5), 371.

14. Jeffery G H, Bassett J, Mendham J and Denny R C, Vogel's text book of quantitative chemical analysis ( $5^{\text {th }}$ Ed.); ELBS Longmans Limited, London, 1989.

15. Kannan N and Vanangamudi A, Indian J Env Protect., 1991, 11(4), 241.

16. Kannan N, Indian J Environ Protect., 1991, 11(7), 514.

17. Annadurai G and.Krishnan M R V, Indian J Environ Protect., 1996, 16(6), 444.

18. Annadurai G and Krishnan M R V, Indian J Chem Technol., 1997, 4, 214.

19. Weber T W and Chakravorti R K, Am Inst Chem Engg J., 1974, 2, 228.

20. Hall K R, Eagleton L C, Acrivos A and Vermelen T, Ind Engg Chem Fund., 1966, 5, 21.

21. Kannan N and Karrupasamy K, Indian J Environ Protect., 1998, 18(9), 683.

22. Kannan N and Meenakshisundaram M, Water Air Soil Poll., 2002, 138, 289.

23. Kannan N and Xavier A, Toxicol Environ Chem., 2001, 19, 95.

24. Kannan N and Raja Kumar A, Toxicol Environ Chem., 2003, 84(14), 7.

25. Panday K K, Prasad G and Singh V N, Environ Tech. Lett., 1986, 7, 547.

26. Bhattacharya A K and Venkobachar C, J Am Civ Engg., 1984, 110, 10.

27. Mc Kay G, Biochem Eng J., 1983, 27, 187.

28. Deo N and Ali M, Indian J Environ Protect., 1993, 13, 496, 576.

29. Crank G, The mathematics of diffusion; Clarendan Press, London, New Delhi, 1933, 1. 
30. Mc Kay G, Otterburn M S and Sweeny A G, Water Res., 1980, 14, 10.

31. Weber Jr W J, Physicochemical process for water quality control; Wiley Interscience, New York, 1972, 207.

32. Kannan N and Srinivasan T, Indian J Environ Protect., 1998, 18(3), 194. 


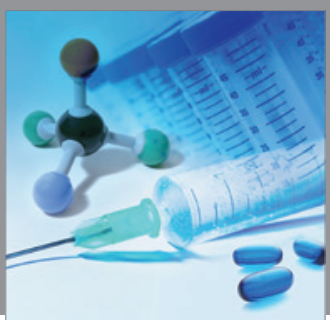

International Journal of

Medicinal Chemistry

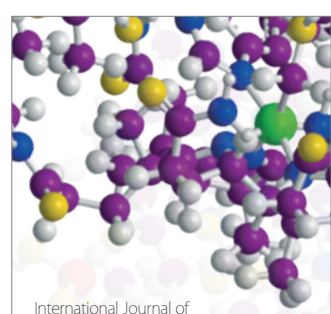

Carbohydrate Chemistry

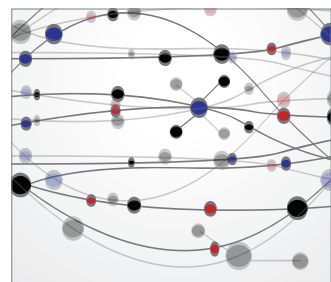

The Scientific World Journal
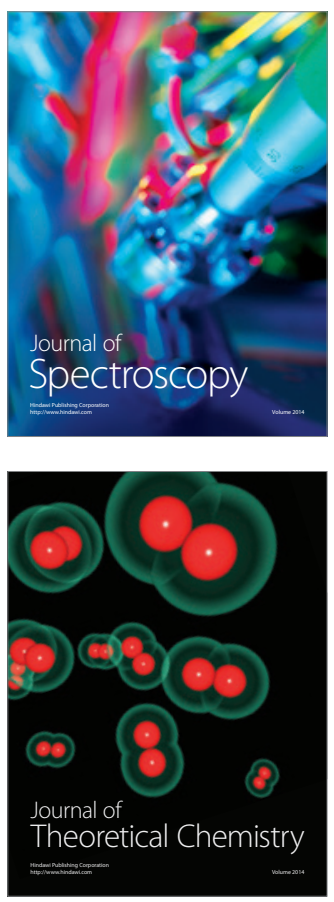
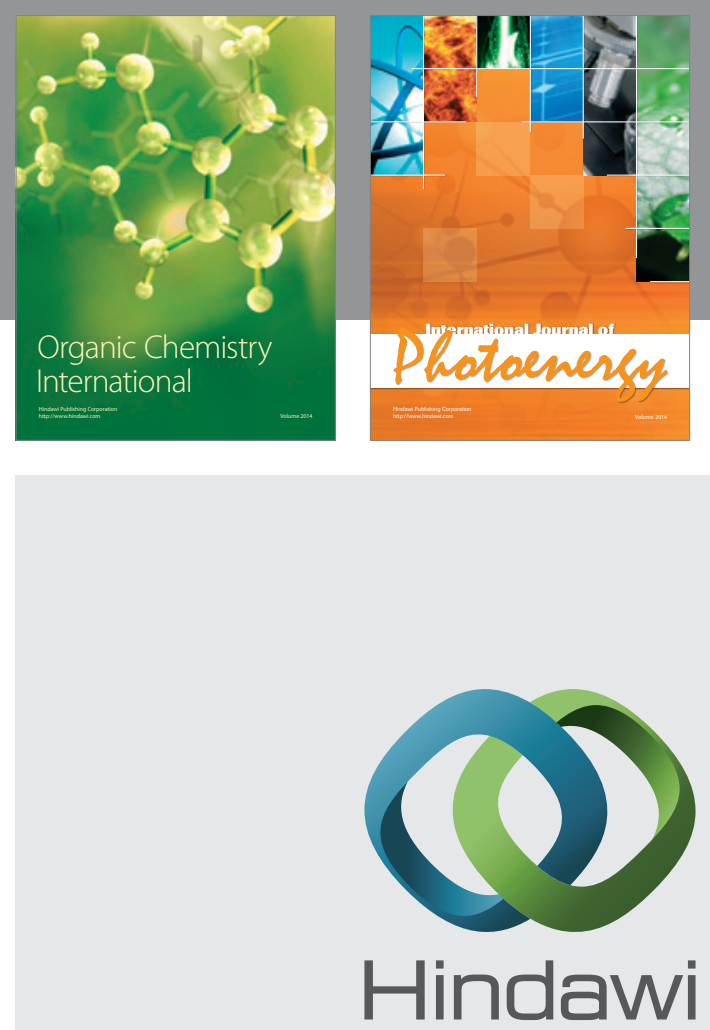

Submit your manuscripts at

http://www.hindawi.com
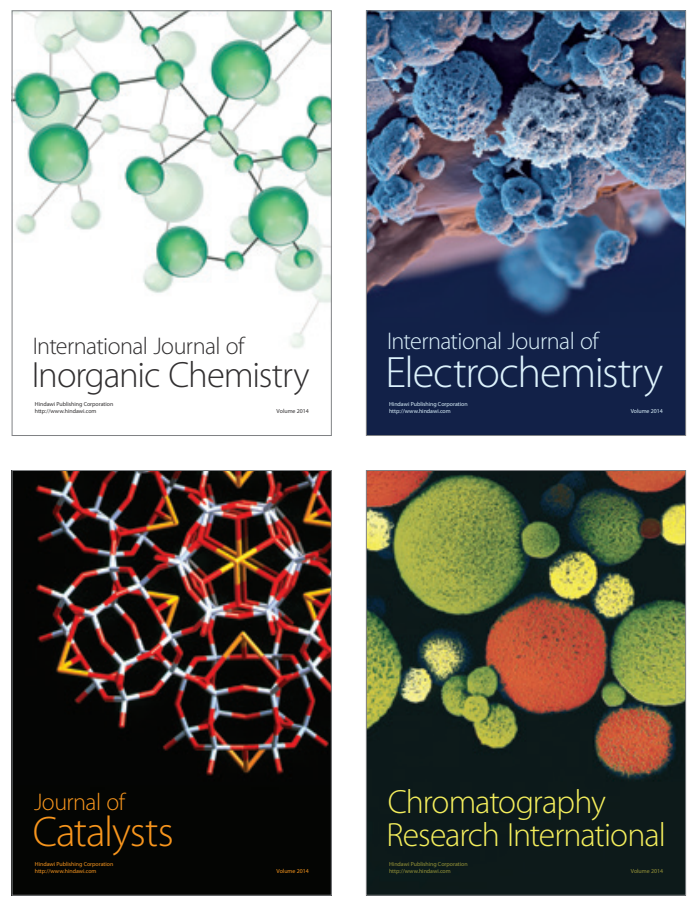
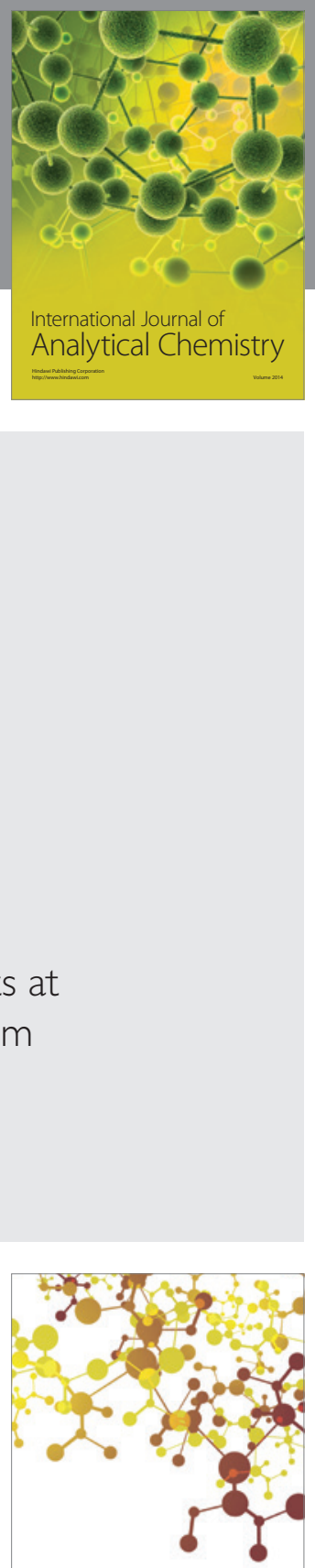

Journal of

Applied Chemistry
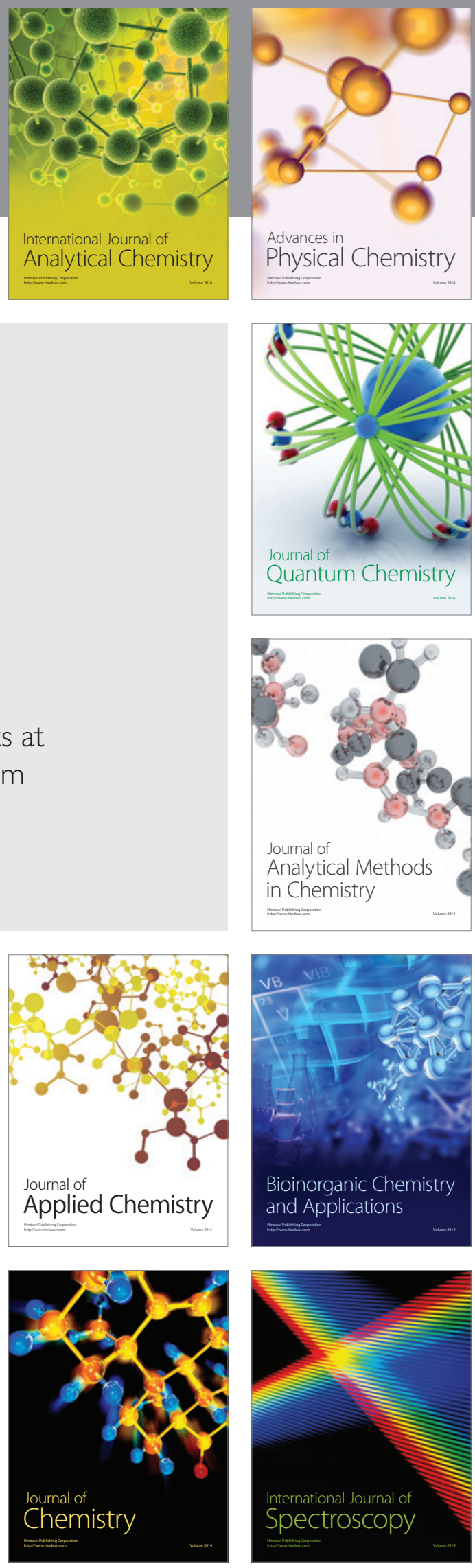